\title{
Alimentos con potencial efecto inmunomodulador y antiviral a propósito de la pandemia COVID-19
}

DOI: 10.17533/udea.penh.v22n2a06

PERSPECTIVAS EN NUTRICIÓN HUMANA

ISSN 0124-4108

Escuela de Nutrición y Dietética, Universidad de Antioquia. Medellín, Colombia

Vol. 23, N. ${ }^{\circ}$ 2, julio-diciembre de 2021, pp. 199-220.

Artículo recibido: 23 de febrero de 2021

Aprobado: 19 de agosto de 2021

Juan Huaccho-Rojas ${ }^{1 *}$; Wendy Yánac-Tellería ${ }^{2}$; Alfonso David Balladares Quintana ${ }^{3}$; Lidsey Carolay Rodríguez Manyari4; Sol Galarza Puertas ${ }^{5}$; José Vallejos-Gamboa ${ }^{6}$; José ArandaVentura7; Martha Villar López ${ }^{8}$

\section{---Resumen}

Antecedentes: los tratamientos con base en medicamentos contra la COVID-19 no han sido aprobados hasta la actualidad. La forma más efectiva de enfrentar este problema de salud pública es la prevención con una adecuada alimentación, medidas de higiene y protección. Los alimentos han sido históricamente utilizados por la población para mejorar su nutrición y complementar el tratamiento o prevención de enfermedades. Se conocen los diversos compuestos bioactivos de algunos alimentos, que en estudios experimentales demostraron su acción antiviral e inmunomoduladora. Objetivo: identificar los compuestos bioactivos o preparados de alimentos con potencial efecto inmunomodulador, inmunoestimulante y antiviral contra el coronavirus. Materiales y métodos: se

$1^{*} \quad$ Autor de correspondencia. Facultad de Medicina Humana, Universidad de San Martín de Porres, Centro de Investigación de Medicina Tradicional y Farmacología. Lima, Perú. drjuanhuaccho@ gmail.com. https://orcid.org/0000-0002-3902-3520

2 Sociedad Científica de San Fernando, Facultad de Medicina, Universidad Nacional Mayor de San Marcos, Lima, Perú. wendy.yanac@unmsm.edu.pe. https://orcid.org/0000-0002-6137-0529

3 Facultad de Farmacia y Bioquímica, Universidad Nacional Mayor de San Marcos, Lima, Perú. alfo.david26@gmail.com. https://orcid.org/0000-0002-3002-2804

4 Facultad de Medicina Humana, Facultad de Medicina, Universidad San Martín de Porres, Lima, Perú. carolayrodriguezm@gmail.com. https://orcid.org/0000-0002-9958-3669

5 Facultad de Medicina Humana, Facultad de Medicina, Universidad Nacional Mayor de San Marcos, Lima, Perú. sol.galarza@unmsm.edu.pe. https://orcid.org/0000-0001-5108-6148

6 Escuela Profesional de Medicina Humana, Facultad de Medicina, Universidad Privada San Juan Bautista, Lima, Perú. joseluis9673@gmail.com. https://orcid.org/0000-0002-8800-6946

7 Instituto de Medicina Tradicional, Seguridad Social de Salud (ESSALUD), Iquitos, Perú. jarandaventura@gmail.com. https://orcid.org/0000-0001-7894-7278

8 Comité de Medicina Tradicional, Alternativa y Complementaria, Médico Peruano Colegio, Perú. mavillar3377@gmail.com. https://orcid.org/0000-0002-3638-8364

Cómo citar este artículo: Huaccho-Rojas J, Yánac-Tellería W, Balladares A, Rodriguez CL, Galarza S, Vallejos-Gamboa J, Aranda-Ventura J, Villar-López M. Alimentos con potencial efecto inmunomodulador y antiviral a propósito de la pandemia COVID-19. Perspect Nutr Humana. 2021;23:199-220. DOI: 10.17533/udea.penh.v23n2a06 
realizó una búsqueda en Google Scholar, Scopus y en la Biblioteca Virtual de Salud en Bases de datos de Medicina Tradicional, Complementaria e Integrativa utilizando los términos food, immunomodulatory, immunostimulatory y antiviral en cuatro búsquedas sucesivas. Resultados: se obtuvieron 93 artículos y se identificó mayor evidencia sobre el efecto antiviral e inmunológico contra el coronavirus en nueve alimentos: Allium sativum, Cinnamomum zeylanicum, Citrus sinensis, Zingiber officinale, Vitis vinífera, Allium cepa, Curcuma longa, Punica granatum y Sambucus nigra. Los cuatro primeros mostraron actividad contra el SARS-CoV-2. Conclusiones: se evidenció el efecto inmunológico y antiviral contra el coronavirus de nueve alimentos; sin embargo, son estudios in silico e in vitro, por ello se requiere mayor investigación preclínica y clínica que lo confirmen.

Palabras clave: antivirales, coronavirus, alimentos nutracéuticos, inmunomodulación, técnicas in vitro.

\section{Potential Immunomodulatory and Antiviral Food Effect in The Context of COVID-19 Pandemic}

\section{Abstract}

Background: Up to date drug-based treatments for COVID-19 have not been approved. The most effective way to face this public health problem is prevention with adequate nutrition, hygiene, and protection measures. Food has historically been used by people to improve their nutrition and complement the treatment or prevention of diseases. The various bioactive compounds of some foods are known, which in experimental studies demonstrated their antiviral and immunomodulatory action. Objective: To identify bioactive compounds of foods or food preparations with potential immunomodulatory, immunostimulatory, and antiviral effects against coronavirus. Material and Methods: A search was carried out in Google Scholar, Scopus, and Virtual Health Library on Traditional Complementary and Integrative Medicine using the terms food, immunomodulatory, immunostimulatory, and antiviral in four successive searches. Results: 93 articles were obtained, and further evidence of antiviral and immunological effect against coronavirus was identified on nine foods: Allium sativum, Cinnamomum zeylanicum, Citrus sinensis, Zingiber officinale, Vitis vinifera, Allium cepa, Curcuma longa, Punica granatum, and Sambucus nigra. The first four of them showed activity against SARS-CoV-2. Conclusions: The immunological and antiviral effect against coronavirus of nine foods was evidenced; however, they are in silico and in vitro studies, therefore it is required further preclinical and clinical research to confirm this.

Keywords: Antivirals, coronavirus, nutraceutical foods, immunomodulation, in vitro techniques.

\section{INTRODUCCIÓN}

El nuevo coronavirus, SARS-CoV-2 (síndrome respiratorio agudo severo coronavirus 2), responsable de la actual pandemia COVID-19 (1), ha tenido, hasta el 10 agosto del 2021, una repercusión de 203295170 casos y 4303515 muertes confirmadas (2), que constituyen un grave problema de salud pública. El SARS-CoV-2 es un virus de ácido ribonucleico (ARN), que pertenece a la familia Coronaviridae y es parte del grupo de los betacoronavirus (3). En años previos a esta pandemia, ocurrieron dos epidemias causadas por otros betacoronavirus: coronavirus del síndrome respiratorio agudo severo (SARS-CoV) y coronavirus del síndrome respiratorio del Medio Oriente (MERS-CoV) (4). El SARS-CoV-2 es similar a estos dos últimos virus, lo cual se sustenta en su proximidad genética. 
Las estrategias terapéuticas para combatir la enfermedad COVID-19 se pueden dirigir a dos objetivos: al virus directamente y a las células del huésped. Sobre el SARS-CoV-2, las dianas serían la proteína de espiga(S), la proteasa similar a 3-quimotripsina (3Clpro), la proteasa similar a papaína (PL pro) y la ARN polimerasa dependiente de $A R N(R d R p)$ (5). Sobre el huésped, específicamente sobre los receptores celulares, las dianas serían la enzima convertidora de angiotensina humana 2(ACE2) (6) y la proteína de choque térmico A5(HSPA5) (7), entre otros receptores en estudio. El sistema inmune sería otra diana del huésped, ya que se conoce que en la patogénesis de esta enfermedad se presenta una disfunción inmune, mediada por la liberación de citocinas y quimiocinas inflamatorias al torrente sanguíneo, reacción conocida como "tormenta de citoquinas". Además, se ha reportado con frecuencia linfopenia (6). Este escenario crea la necesidad de investigar estrategias terapéuticas inmunomoduladoras.

A pesar de los grandes esfuerzos para manejar esta enfermedad, aún no hay terapias antivirales establecidas para los coronavirus (8). En este contexto, se justifica recurrir a diversas líneas de investigación, es el caso de los estudios de los compuestos bioactivos de los alimentos como fuente de moléculas con potencial efecto sobre la salud humana; en esta área de estudio el término más conocido es alimento funcional, el cual fue usado por primera vez en Japón para denominar a los alimentos que contienen ingredientes con funciones para la salud humana (9). Se ha reportado que algunos alimentos tienen efecto antiviral e inmunomodulador. Un precedente importante fue el descubrimiento del ácido shikímico en una especia de cocina, el Illicium verum (anís estrellado), compuesto que sirvió de base para el desarrollo del antiviral oseltamivir fosfato (10).
En medio de esta crisis global por COVID-19, el análisis del conocimiento de los principios bioactivos de los alimentos con propiedades antivirales e inmunomoduladoras es importante porque sería el primer paso para desarrollar nuevas líneas de investigación con compuestos activos como un potencial recurso de nuevos fármacos, lo que también ayudaría a verificar su uso en la prevención de esta enfermedad. Por tal motivo, el objetivo de la presente revisión fue reportar alimentos de uso común y sus componentes bioactivos con potenciales efectos antivirales e inmunológicos. Por lo tanto, se resume la información de los alimentos y su mecanismo de acción con base en artículos publicados que involucran información sobre coronavirus.

\section{MATERIALES Y MÉTODOS}

Se realizó una primera búsqueda en Google Scholar, Scopus y en la Biblioteca Virtual de Salud en Bases de datos de Medicina Tradicional, Complementaria e Integrativa (BVS-MTCI), otras bases de datos fueron excluidas por temas de tiempo y accesibilidad. Se cruzó el descriptor MESH food y los términos immunomodulatory, immunostimulatory y antiviral utilizando el operador booleano "AND" para cada uno de los cruces, tanto en español como en inglés. La búsqueda de artículos se realizó sin exclusión de año de publicación durante los meses de abril y mayo del 2020; se obtuvieron 290 artículos y se identificaron 81 alimentos con dichos efectos. Posteriormente, se seleccionaron los 17 alimentos con mayor evidencia científica.

En la segunda búsqueda, se cruzó el nombre científico, el nombre común y los descriptores immunomodulatory, immunostimulatory y antiviral utilizando el operador booleano "AND", tanto en español como en inglés, con un resultado de 282051 artículos científicos. En una tercera búsqueda, se cruzó el nombre científico, el nombre 
común y el descriptor MESH coronavirus; se obtuvieron nueve alimentos.

Se realizó una cuarta búsqueda para cada alimento seleccionado, cruzando el nombre científico, el nombre común y las variables immunomodulatory, immunostimulatory y antiviral, utilizando el operador booleano "AND" para cada uno de los cruces ya mencionados, tanto en español como en inglés. El resultado fue de 211 artículos, de los cuales se priorizó la selección de artículos originales y ensayos clínicos, mediante el criterio de los expertos. Se incluyeron revisiones narrativas con el fin de extraer información sobre las propiedades de los alimentos, su estructura y composición bioquímica. Estas no aportan evidencia original para sustentar algún efecto farmacológico. El resultado final fue de 93 artículos. El proceso de selección de los artículos se muestra en la figura 1.

\section{RESULTADOS Y DISCUSIÓN}

\section{Efecto potencial inmunológico y antiviral}

En la búsqueda realizada se encontraron nueve alimentos con potencial efecto inmunomodulador, inmunoestimulante y antiviral en coronavirus, que se describen en la tabla 1.

\section{Allium sativum $\mathrm{L}$.}

Comúnmente llamado ajo, pertenece a la familia Amaryllidaceae, originaria de Asia, actualmente con una distribución cosmopolita. La parte de la planta que se utiliza es el bulbo, que tiene gran cantidad de compuestos organosulfurados como alína, alicina, ajoeno, disulfuro de dialilo (DADS), entre otros. En el bulbo fresco e intacto, el componente principal es aliína, pero cuando se tritura, la aliína se transforma en alicina, el compuesto sulfurado más bioactivo (11). DADS es otro componente importante responsable de los efectos biológicos (12). Además, se ha reportado la pre- sencia de antocianinas (AT) y flavonoles como kaempferol, miricetina y quercetina (13).

En los últimos años, se ha realizado una amplia variedad de estudios con moléculas aisladas. La alicina ha demostrado efectos inmunomoduladores en macrófagos infectados con Mycobacterium tuberculosis, como la estimulación de la respuesta protectora Th1 en modelos murinos (14). Los fructanos (14-17\% en composición fresca), que se encuentran principalmente en el bulbo, son capaces de aumentar la actividad inmune a través de la proliferación de esplenocitos murinos, macrófagos peritoneales y actividad fagocítica in vitro (15).

EI DADS también demostró un efecto inmunoestimulante con la expresión de MUC5B, proteína regulada por la vía de señalización Extracellular signal-regulated kinases/Mitogen-activated protein kinases (ERK 2/MAPK) de las células del epitelio respiratorio humano e involucrada en la protección y lubricación de la superficie del tracto respiratorio (12). Las lectinas presentes en el ajo también reportaron efectos mitógenos sobre linfocitos, basófilos y mastocitos (16). Una revisión de los componentes del género Allium muestra que la alicina reduce la expresión de la óxido nítrico sintasa inducible y la acumulación de óxido nítrico (NO), también reduce los niveles de factor de necrosis tumoral alfa (TNF- $\alpha$ ), factor nuclear potenciador de cadena ligera kappa de células $B$ activadas (NF-кB), Interleukina-1 (IL-1) e IL-6; mientras que el ajoeno, un metabolito de la alicina, inhibe la producción de NO y prostaglandina E2 (PGE-2), así como la expresión de citocinas proinflamatorias; otro efecto del DADS consiste en disminuir los niveles de TNF- $\alpha$ y otras interleucinas (17).

Una gran cantidad de virus son sensibles al extracto de ajo. Los efectos antivirales de los componentes de un extracto se evaluaron en virus ADN como el virus del herpes simple tipo 1, el virus del 
herpes simple tipo 2 y el virus vaccinia, y en virus ARN como el virus de la parainfluenza tipo 3, el virus de la estomatitis vesicular y el rinovirus tipo 2. El orden de los componentes de mayor actividad antiviral in vitro fue el ajoeno (solo presente en el extracto de ajo añejo), seguido de la alicina, el alil metil tiosulfinato y el metil alil tiosulfinato (18). En otro estudio, los extractos etanólico y metanólico de $A$. sativum mostraron un ligero efecto en la hemaglutinación y fueron capaces de inhibir la actividad de la polimerasa viral y la síntesis de nucleoproteínas del virus de la influenza $\mathrm{A}$ (H1N1) pdm09 (19).

En la familia de los coronavirus, se ha reportado el efecto del extracto acuoso de ajo (conformado por varios compuestos organosulfurados, con predominio del DADS) sobre dos cadenas del virus de la bronquitis infecciosa aviar (IBV), 4/91(intervet) y el M41. Este experimento fue realizado en embriones de pollo, en los que se observó un efecto antiviral significativo (20). En un estudio in silico, el efecto de 17 compuestos organosulfurados del aceite esencial sugirió la acción de estos en el SARS-CoV-2. Se observó especialmente en el disulfuro y trisulfuro de alilo (que representan el 51,3\% del aceite esencial), que actuarían inhibiendo la proteína ACE2, lo cual bloquearía la unión del virus a esta molécula, e inhibiendo a la proteasa principal PDB6LU7 del SARS-CoV-2, esto a su vez evitaría la maduración de las proteínas del virus y, en consecuencia, la propagación de la infección (21).
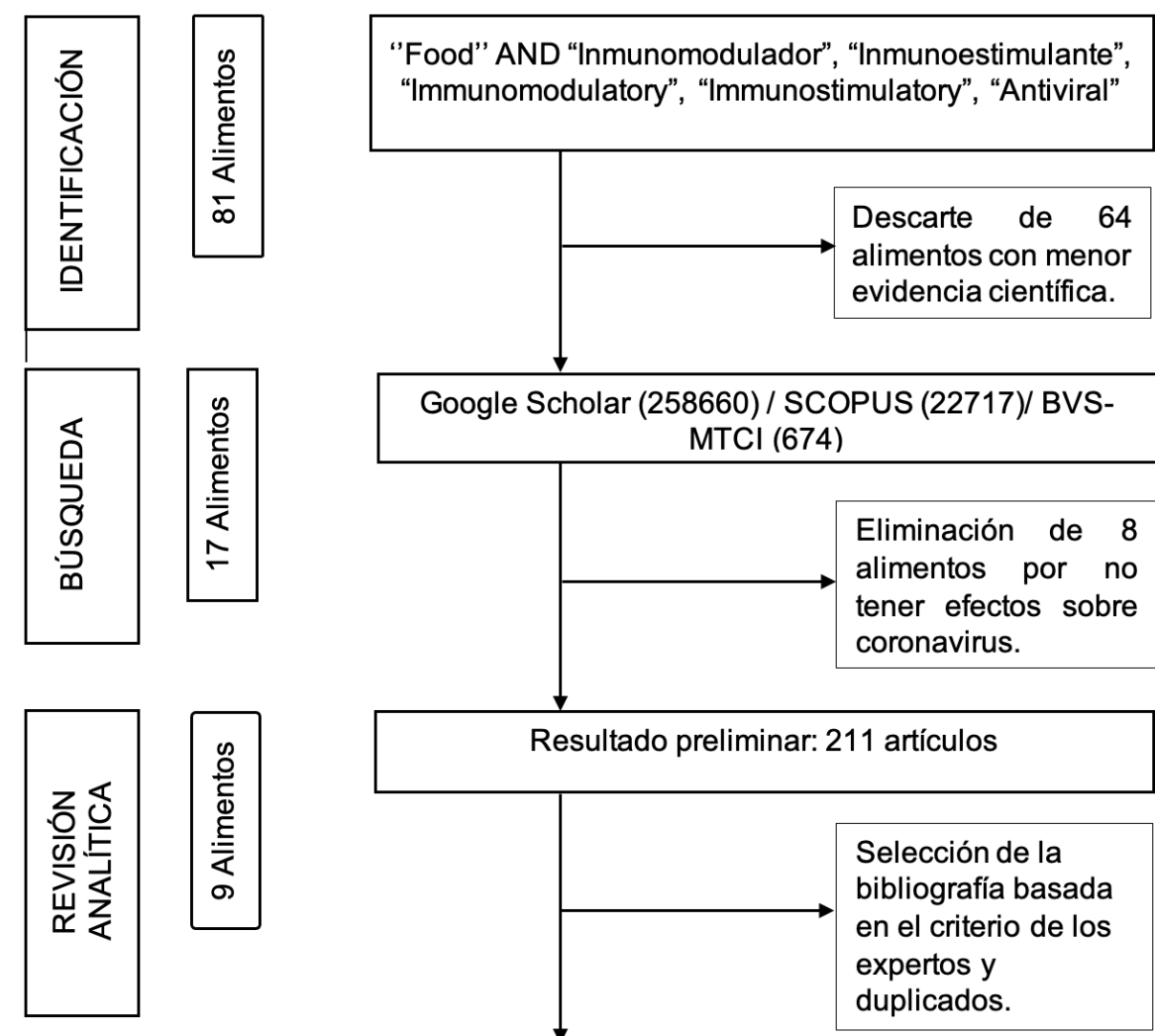

Resultado final: 93 artículos

Figura 1. Diagrama de flujo de la selección de artículos 


\section{Alimentos con potencial efecto inmunomodulador y antiviral}

Tabla 1. Actividad antiviral potencial sobre coronavirus y efecto inmunomodulador por compuestos bioactivos de alimentos

\begin{tabular}{|c|c|c|c|c|c|}
\hline \multirow[t]{2}{*}{ Alimento fuente } & \multicolumn{4}{|c|}{ Efecto antiviral de compuesto/preparado } & \multirow{2}{*}{$\begin{array}{l}\text { Efecto inmunomodulador/ } \\
\text { inmunoestimulante }\end{array}$} \\
\hline & $\begin{array}{l}\text { Compuestos } \\
\text { bioactivos }\end{array}$ & $\begin{array}{l}\text { Tipo de } \\
\text { coronavirus }\end{array}$ & $\begin{array}{l}\text { Efecto } \\
\text { antiviral }\end{array}$ & $\begin{array}{l}\text { Tipo de } \\
\text { estudio }\end{array}$ & \\
\hline Allium sativum $\mathrm{L}$. & $\begin{array}{l}17 \text { compuestos } \\
\text { organosulfurados } \\
\text { (disulfuro y } \\
\text { trisulfuro de alilo, } \\
\text { los de mayor } \\
\text { actividad) }\end{array}$ & $\begin{array}{l}\text { S A R S - } \\
\text { CoV-2 }\end{array}$ & $\begin{array}{l}\text { Inhibe las } \\
\text { proteínas: } \\
\text { ACE2, } \\
\text { PDB6LU7 }\end{array}$ & In silico & $\begin{array}{l}\text {-Alicina tiene efecto inmunomodulador in } \\
\text { vitro e in vivo en macrófagos infectados con } \\
\text { Mycobacterium tuberculosis. } \\
\text {-Alicina reduce iNOS, NO, TNF- } \alpha, N F-\kappa B \text {, } \\
\text { IL-1, IL-6. } \\
\text {-DADS, disminuye los niveles de TNF- } \alpha \text { y } \\
\text { otras interleucinas. También demostró efecto } \\
\text { inmunoestimulante mediante la expresión de } \\
\text { MUC5B, a través de la vía ERK2/MAPK de } \\
\text { las células del epitelio respiratorio humano. }\end{array}$ \\
\hline Allium cepa L. & Quercetina & $\begin{array}{l}\text { virus del } \\
\text { pseudotipo } \\
\text { HIV-luc } \\
\text { SARS } \\
\text { SARS-CoV }\end{array}$ & $\begin{array}{l}\text { Inhibidor la } \\
\text { replicación } \\
\text { viral }\end{array}$ & In silico & $\begin{array}{l}\text {-Extracto de cebolla inhibe concentraciones } \\
\text { de citocinas proinflamatorias IL-6, IL-8, } \\
\text { TNF- } \alpha \text { en hiperplasia benigna de próstata; } \\
\text { reduce citocinas Th2 (IL-4, IL-5, e IL13 b) al } \\
\text { actuar en la vía NF-kB. } \\
\text {-DAS, DADS y fructooligosacáridos } \\
\text { aumentan la celularidad de los órganos } \\
\text { linfoides. } \\
\text {-Lectinas de la cebolla incrementan } \\
\text { moléculas proinflamatorias (COX-2, NO, } \\
\text { TNF- } \alpha \text { ) en ratas inmunosuprimidas por CTX; } \\
\text { aumentan las citocinas proinflamatorias. } \\
\text { TNF- } \alpha \text { e IL-12 y la estimulación de } \\
\text { respuesta linfocitaria Th1 en ratas no } \\
\text { inmunosuprimidas. }\end{array}$ \\
\hline $\begin{array}{l}\text { Cinnamomum } \\
\text { zeylanicum Blume }\end{array}$ & Cinnamaldehido & $\begin{array}{l}\text { S A R S - } \\
\text { CoV-2 }\end{array}$ & $\begin{array}{l}\text { Inhibidor de } \\
\text { HSPA5 }\end{array}$ & In silico & $\begin{array}{l}\text {-El extracto polifenólico de canela regula la } \\
\text { respuesta inmune a través de los genes que } \\
\text { codifican la TTP y promueven las citocinas } \\
\text { proinflamatorias. } \\
\text {-El extracto etanólico reduce los niveles de } \\
\text { citocinas proinflamatorias como el TNF- } \alpha \text {, IL- } \\
-1 \beta \text {, IFN- } \alpha \text { e incrementa la producción de } \\
\text { TGF- } \beta \text { que tiene acción antinflamatoria. }\end{array}$ \\
\hline Citrus sinensis L. & $\begin{array}{l}\text { Hesperetin, } \\
\text { naringenin, } \\
\text { naringin }\end{array}$ & $\begin{array}{l}\text { S A R S - } \\
\text { CoV-2 }\end{array}$ & $\begin{array}{l}\text { Inhibidor de } \\
\text { ACE2 }\end{array}$ & In silico & $\begin{array}{l}\text {-La naringina, inhibe citocinas } \\
\text { proinflamatorias (COX-2, iNOS, IL-1 } \beta, I L-6 \text { ) } \\
\text {-Jugo de naranja (hesperidina, naringenina, } \\
\text { vitamina C) disminuye marcadores } \\
\text { inflamatorios (NF- } \mathrm{KB}, \mathrm{CRP}, \mathrm{IL}-1, \mathrm{IL}-6, \mathrm{TLR}) \\
\text { y la expresión de genes proinflamatorios } \\
\text { (CCL26, CX3CR1, MCP-1). } \\
\text {-ROC* inhibió la producción de ICAM-1, e } \\
\text { redujo IL-8 y la MCP-1 en queratinocitos } \\
\text { normales estimulados con IFN- } \gamma \text { e histamina. }\end{array}$ \\
\hline
\end{tabular}


Curcuma longa L. curcumina

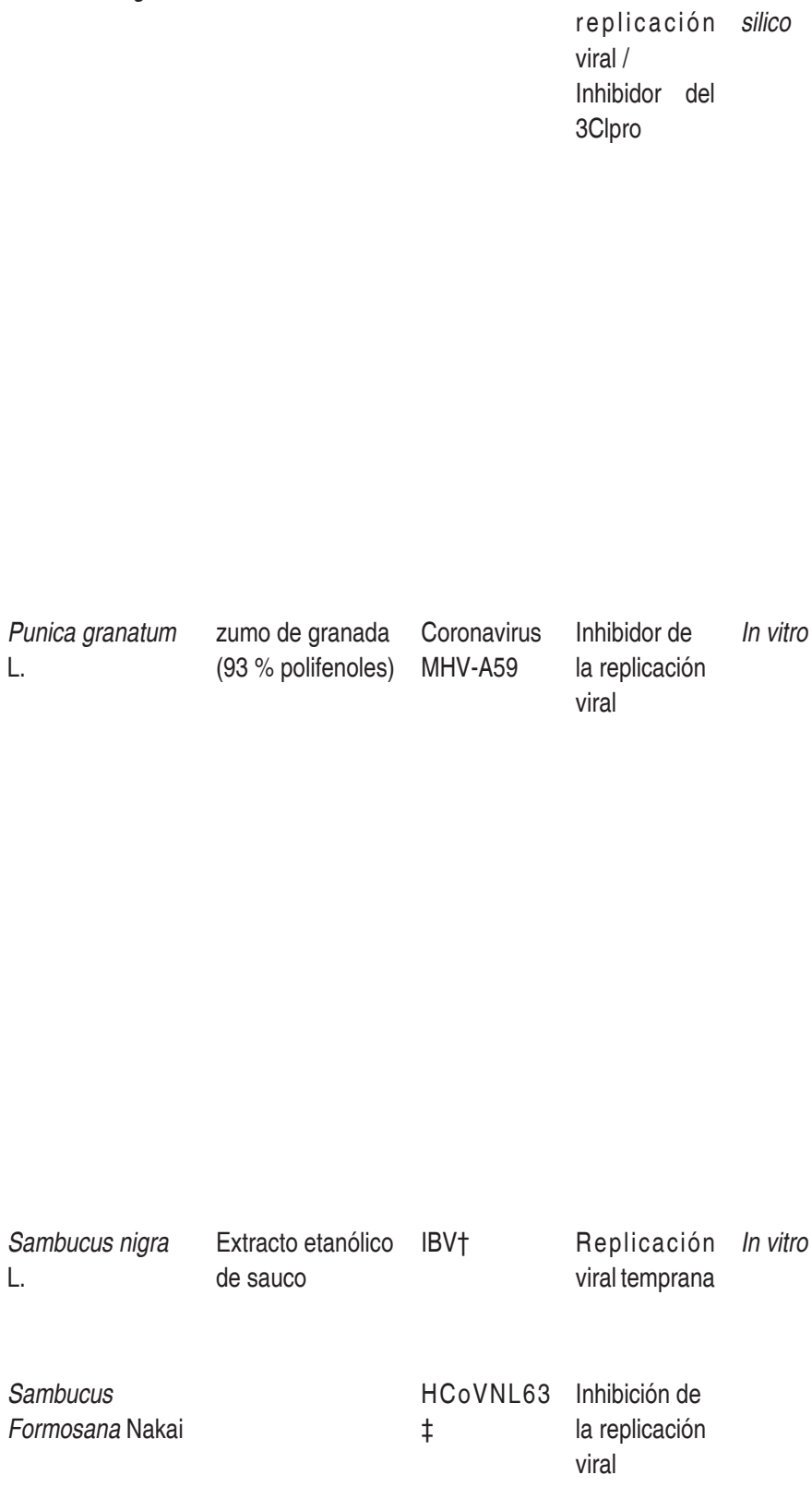

- La curcumina regula las citocinas MCP-1, IL-6 y TNF- $\alpha$ durante la infección por el virus de la influenza $A$. Regula al IFN- $\beta$ y el TNF- $\alpha$ y la expresión de RNAm de estas citocinas durante la infección por el virus de la influenza aviar (H5N1). Tiene efecto antiinflamatorio, y disminuye los niveles de TLR4 y NF-KB.

- La tetrahidrocurcumina redujo los niveles de citocinas Th2 (IL -4, IL -5, y IL -13), además de aumentar los niveles de linfocitos y monocitos.

- Los aceites esenciales ( $\alpha$-turmerone y ar -turmerone) tienen efecto antiinflamatorio, ejerciendo actividades moduladoras sobre las PBMC.

- Los polisacáridos tienen efecto inmunoestimulante sobre PBMC.

- Los extractos de granada y el ácido elágico disminuyen los mediadores inflamatorios: IL-6, IL-17, IL-12, IL-8, IL-13, IL-5, IL-4, IL-18, PGE-2, NO, COX-2,ONS, IL-2 e IL-1 $\beta$.

- Los polisacáridos de la cáscara de la granada inducen a los macrófagos a liberar mediadores como NO, IL-1 $\beta$, TNF- $\alpha$, IL-6 e IL-10. Estimulan la proliferación y secreción de linfocitos esplénicos y aumentan la expresión de lg-A, lg-G e lg-M, así como la liberación de citocinas (TNF- $\alpha$, IL-2 e INF- $\gamma$ ). - El extracto de granada tiene un efecto inmunomodulador potencial sobre la producción de citocinas en la infección por coronavirus. La granada tiene un efecto antiinflamatorio a través de la activación de PPAR- $\gamma$.

- El extracto etanólico al 96 \% disminuye la producción de NO.

- El jugo de sauco aumentó la producción de IL-6, IL-8 y TNF.

- El extracto de sauco rico en polifenoles aumentó valores de TNF- $\alpha$ y IFN- $\gamma$ y redujo los valores del marcador inflamatorio fibrinógeno. 


\section{Alimentos con potencial efecto inmunomodulador y antiviral}

\begin{tabular}{|c|c|c|c|c|c|}
\hline Vitis vinífera L. & Resveratrol & MERS-CoV & $\begin{array}{l}\text { Inhibición de } \\
\text { la replicación } \\
\text { viral }\end{array}$ & In vitro & $\begin{array}{l}\text { - El extracto de semillas de uvas (flavonoides } \\
\text { y fenoles) inhibe la expresión de citocinas } \\
\text { Th2-derivadas como IL-6, e induce } \\
\text { selectivamente la producción de citocinas } \\
\text { Th1-derivadas IFN- } \gamma \text { por PBMC. } \\
\text { - Las proantocianidinas de las semillas de } \\
\text { uvas tienen efecto inmunoestimulante en la } \\
\text { inmunidad humoral y celular, promoviendo } \\
\text { la proliferación de linfocitos, mejorando la } \\
\text { fagocitosis de macrófagos peritoneales y } \\
\text { aumentando la liberación de moléculas } \\
\text { efectoras producidas por macrófagos. } \\
\text { - EPSU: suprimió la expresión de IL-1 } \beta \text {, IL-6 } \\
\text { y de IL-8 inducidas por RSV. Esto sugiere } \\
\text { que EPSU es un agente preventivo en } \\
\text { enfermedades respiratorias inducidas por } \\
\text { RSV. }\end{array}$ \\
\hline \multirow[t]{4}{*}{$\begin{array}{l}\text { Zingiber officinale } \\
\text { Rosc. }\end{array}$} & 6-Gingerol & $\begin{array}{l}\text { S A R S - } \\
\text { CoV-2 }\end{array}$ & $\begin{array}{l}\text { Inhibidor } \\
\text { del ACE2, } \\
\text { unión débil } \\
\text { a proteasa } \\
\text { MPRO }\end{array}$ & In silico & $\begin{array}{l}\text { El gingerol muestra un efecto } \\
\text { antiinflamatorio a través de la inhibición de } \\
\text { linfocitos Th1 y Th2 en cultivos polarizados, } \\
\text { supresión de genes que expresan IFN- } \gamma \text { e } \\
\text { IL-4, disminución del factor de transcripción } \\
\text { AP1 y de la vía NF- } \mathrm{KB} \text {. }\end{array}$ \\
\hline & 6-Shogaol & $\begin{array}{l}\text { S A R S - } \\
\text { CoV-2 }\end{array}$ & $\begin{array}{l}\text { Unión débil } \\
\text { a proteasa } \\
\text { MPRO }\end{array}$ & In silico & $\begin{array}{l}\text { - El extracto acuso de kion (rico en } \\
\text { gingeroles, shogaol y paradol), a nivel } \\
\text { celular, actúa inhibiendo la activación de } \\
\text { macrófagos y neutrófilos, acompañado de } \\
\text { disminución en la migración de monocitos } \\
\text { y leucocitos. A nivel molecular, actúa } \\
\text { disminuyendo citoquinas proinflamatorias }\end{array}$ \\
\hline & & & & & $\begin{array}{l}\text { (TNF } \alpha, \text { IL6, IL1 } \beta, \text { MCP-1)y quimiocinas. } \\
\text { - La cápsula de kion en polvo (estudio clínico) } \\
\text { reporta disminución en los niveles séricos }\end{array}$ \\
\hline & & & & & $\begin{array}{l}\text { de TNF } \alpha \text { e IL1 } \beta \text {. En comparación con el } \\
\text { grupo control, también muestra inhibición de } \\
\text { PGE-2, así como supresión de COX2. }\end{array}$ \\
\hline
\end{tabular}

* ROC: Red orange complex, mezcla de jugo de naranja con altos niveles de antocianinas, flavanonas, ácidos hidroxicinámicos y ácido ascór- bico. † IBV: virus de la bronquitis infecciosa, un coronavirus tipo gamma que produce patogenia en aves. $\ddagger$ HCoVNL63: coronavirus humano VNL63, un coronavirus de tipo alfa que ocasiona enfermedad del tracto respiratorio alto y bajo (bronquiolitis, y neumonía). ACE2: enzima convertidora de angiotensina-2; PDB6LU7: proteasa principal de SARS-CoV-2; iNOS: óxido nítrico sintasa inducible; NO: óxido nítrico; TNF- $\alpha$ : factor de necrosis tumoral alfa; NF-кB: factor nuclear potenciador de las cadenas ligeras kappa de células B activadas; DADS: disulfuro de dialilo; ERK2/MAPK: extracellular signal regulated kinases-2/mitogen-activated protein kinases; IL: interleukina; DAS: dialil disulfuro; CTX, ciclofosfamida; COX-2: ciclooxigenasa-2; CRP: proteína C reactiva; TLR: receptor de tipo toll; ROC: Red orange complex; ICAM-1: molécula de adhesión intercelular-1; MCP-1: proteína quimiotáctica de monocitos-1; IFN- $\gamma$ : interferón gamma; 3Clpro: proteasa similar a 3-quimotripsina; PLpro: proteasa similar a papaína; IFN- $\beta$ : interferón-beta; PBMC: célula mononuclear de sangre periférica; HSPA5: miembro de la familia A de proteínas de choque térmico 5; TTP: proteína tristetraprolina; TGF- $\beta$ : factor de crecimiento transformante beta; PGE-2: prostaglandina-E2; PPAR- $\gamma$ : receptor gamma activado por proliferador de peroxisoma; GSPE: extracto de proantocianidina de semilla de uva; RSV: virus sincitial respiratorio; RdRp: ARN-polimerasa dependiente de ARN; AP1: proteína activadora-1; MPRO protease: proteasa MPRO; LPS: lipopolisacárido; MHV-A59: coronavirus murino "virus de la hepatitis de ratón-A59"; CCL26: ligando 26 de quimiocina con motivo C-C o citocina CCL26; C3XCR1: receptor 1 de quimiocinas con motivo C-X3-C1. 
Además, deben mencionarse las propiedades inhibidoras de la agregación plaquetaria del ajo. Se considera que la alicina tiene un papel importante, aunque otros argumentan que sería el ajoeno. Los mecanismos de acción incluyen la reducción de la síntesis de tromboxanos a través de la inhibición de la ciclooxigenasa y lipoxigenasa, junto con el efecto inhibidor sobre los receptores plaquetarios de adenosina difosfato, colágeno y fibrinógeno, y sobre la activación de los trombocitos (22). Esta propiedad del Allium sativum podría disminuir los eventos trombóticos presentes en la fisiopatología de la COVID-19; sin embargo, se necesita más investigación.

\section{Allium cepa L.}

Esta especie se conoce comúnmente como cebolla y pertenece a la familia Amaryllidaceae. El bulbo es la parte comestible y posee hojas modificadas gruesas y en capas. Estas tienen las propiedades bioactivas de la planta gracias a compuestos como fitoesteroles, saponinas y son una gran fuente de flavonoides (flavonoles y AT). Dentro de este último grupo, los compuestos más conocidos son la quercetina, el kaempferol, la miricetina y la catequina, los cuales presentan propiedades antioxidantes, antibacterianas, antialérgicas, antiinflamatorias y antivirales (23).

Dado que el ajo y la cebolla pertenecen a la misma familia de verduras, ambos comparten propiedades inmunoestimuladoras. En un experimento en pollos alimentados con ajo y cebolla con $10 \mathrm{~g} / \mathrm{kg}$ en polvo de cada complemento alimenticio, se observó el aumento de volumen de tejidos linfoides, especialmente con el ajo. Ambos componentes aumentaron la producción de anticuerpos contra el virus Newcastle, y en respuesta a la inoculación de eritrocitos de oveja (24).
El extracto metanólico de cebolla, estandarizado con $60 \%$ de flavonoles y $16 \%$ de quercetina, ha demostrado efecto potencial antiinflamatorio a través de la modulación de la expresión de citocinas proinflamatorias (reduciendo IL-6, IL-8 y TNF- $\alpha$ ) en ratas con hiperplasia de próstata (25). El extracto también se ha estudiado en enfermedades inflamatorias como el asma, en las que la disminución de citocinas Th2, como IL-4, IL-5 e IL$13 b$, reduce la señalización de la vía NF-кB (26).

Sus propiedades inmunomoduladoras se han descrito en diferentes compuestos tales como el sulfuro de dialilo (DAS) y DADS que aumentan la celularidad del tejido linfoide (27). Otros componentes bioactivos como los fructooligosacáridos aumentan la actividad fagocítica en macrófagos murinos (28). Las lectinas han mostrado inmunoestimulación incluso en casos de ratas inmunodeprimidas con ciclofosfamida, por aumento de moléculas proinflamatorias como ciclooxigenasa (COX-2), NO y TNF- $\alpha$ (29). Su efecto también se ha observado en líneas celulares murinas normales que mostraban un aumento de citocinas proinflamatorias (TNF- $\alpha$ e IL-12) y la estimulación de la respuesta Th1 (30).

En cuanto al efecto antiviral, la revisión de Batiha et al. (31) resume una amplia gama de virus que han sido afectados por la cebolla, como el virus linfotrópico de células T humanas-1 y el virus de la encefalitis japonesa. El flavonoide querce- tina ha demostrado actividad contra el virus del dengue tipo 2 y el virus de la hepatitis $C$, el virus de la diarrea epidémica porcina y el virus de la influenza A. Este compuesto también se ha estudiado en los coronavirus, y se ha demostrado la inhibición del virus del pseudotipo HIV-luc/SARS en células Vero E6 in silico (32). Otros estudios de acoplamiento molecular mostraron la inhibición de 3CLpro de SARS-CoV, una proteína necesaria para la replicación del virus (33). 
Este último efecto sugiere que el mecanismo de acción en la infección por coronavirus es similar al efecto del ajo. La evidencia en estudios preclínicos y clínicos es escasa; sin embargo, su efecto predominantemente inmunoestimulador sugiere una potencial acción preventiva de este alimento frente a las infecciones virales.

\section{Cinnamomum zeylanicum Blume}

Comúnmente llamado canela, es un árbol perenne perteneciente a la familia Lauraceae, es originario de Asia y actualmente se cultiva en todo el mundo. Contiene principalmente cinceilanina, ácido ferúlico, ácido cafeico, ácido gálico, ácido vanílico, ácido protocatecuico y p-cumárico junto con polifenoles. Es importante señalar que el cinamaldehído es la sustancia más abundante que se extrae del aceite esencial de la corteza y tiene efectos pleiotrópicos, es decir que puede modular múltiples vías de señalización molecular, lo que implica diferentes efectos farmacológicos (34).

Varios estudios muestran la actividad inmunomoduladora de la canela, entre los que se puede mencionar una investigación realizada con macrófagos murinos RAW 264.7, en los que se evaluó el extracto polifenólico de la canela. Los resultados obtenidos sugieren que este extracto modula la respuesta inmune a través de los genes que codifican la tristetraprolina TTP (proteína con efecto antiinflamatorio al desestabilizar ARNm proinflamatorio) y promueve citocinas proinflamatorias (35). En otro estudio, se verificó la capacidad del extracto etanólico para reducir los niveles de citocinas proinflamatorias como TNF- $\alpha$ e IL-1 $\beta$ y el aumento de la producción del factor de crecimiento transformante beta (TGF- $\beta$ ), que tiene propiedades antiinflamatorias (36). Asimismo, el extracto acuoso redujo el IFN- $\gamma$ en ratones (37).
Sobre su efecto antivírico, la cinzeylanina obtenida de una purificación del extracto acuoso de Cinnamomum zeylanicum y Cinnamomum cassia mostró una capacidad inhibitoria contra la proliferación del virus HSV-1 en células Vero, mediante un ensayo de reducción de placa (38). También, se ha probado la actividad del cinamaldehído contra la infección por adenovirus in vitro; además, se han documentado daños directos al virus y una inhibición de la replicación viral dependiente de su concentración (39). Una procianidina aislada del extracto etanólico de canela también posee actividad contra el virus del $\mathrm{VIH}$, durante la fase de infección, cuando el virus luego de adherirse al receptor CD4 de los linfocitos pasa a unirse a los correceptores X4 y R5, allí es donde actúa el extracto de canela inhibiendo a estos dos correceptores, además regresa la función de los linfocitos a la normalidad (40).

Una serie de fitocompuestos fueron evaluados en experimentos de acoplamiento molecular; se demostró que tienen una fuerte afinidad de unión por HSP-A5 de la superficie celular, que es otro receptor del huésped que también es reconocido: la proteína spike (S) del SARS-CoV-2, por lo que los compuestos que se unen a este receptor pueden interferir con la unión de este virus a la célula. El cinamaldehído fue uno de estos compuestos que mostró que puede unirse fuertemente a HSP-A5, lo que implica que puede afectar el reconocimiento y unión de la proteína $S$ de SARSCov-2 (7).

En general, la canela es una especia que tiene compuestos activos como los polifenoles, que exhiben una actividad inmunomoduladora; además, la cinnzeilanina y el cinamaldehído, que presentan una actividad antiviral. 


\section{Citrus sinensis $\mathrm{L}$.}

Conocida como naranja dulce, pertenece a la familia Rutaceae. Su fruto es comúnmente utilizado como alimento y su cáscara se consume como bebidas de infusión en algunas partes de Asia y África. El extracto de su cáscara es rico en flavonoides, limoneno y linalol (41). El contenido de flavonoides, en orden descendente, es hesperetina, hesperidina, naringenina, neohesperidina, naringina y nobiletina (42). En una mezcla de jugo de variedades de Citrus sinensis (Moro, Tarocco, Sanguinello), llamada red orange complex (ROC), se determinó los altos niveles de AT, ácidos hidroxicinámicos, ácido ascórbico y flavanonas (43). El jugo de naranja (JN) es principalmente una fuente de vitamina $\mathrm{C}$ y flavanonas (hesperidina, naringenina), estas últimas son flavonoides de gran biodisponibilidad (44).

Con respecto a su efecto antiviral, el extracto etanólico de la cáscara de naranja disminuyó la replicación in vitro de un tipo de coronavirus, el MHV-A59 (45). En un estudio de acoplamiento molecular, la hesperetina, la naringina y la naringenina mostraron afinidad de unión al receptor ACE-2, inhibiendo potencialmente la unión del SARS-CoV-2 a la célula huésped (42). En otro estudio in silico, se reportó que la herperidina inhibe la proteasa 3 Clpro del SARS-CoV-2, mientras que la neohesperidina inhibe las proteasas PLpro y 3 Clpro, mecanismos inhibitorios de la replicación viral (5).

La naringina del extracto de cáscara de naranja inhibió la expresión de citocinas proinflamatorias (COX-2, iNOS, IL-1 $\beta$, IL-6) en un modelo inflamatorio inducido por LPS in vitro (42). El ROC es capaz de inhibir la producción de la molécula de adhesión intercelular-1 (ICAM-1), IL-8 y la proteína quimioatrayente de monocitos 1(MCP-1) en queratinocitos normales estimulados con IFN- $\gamma$ e histamina.
En este experimento, el ROC tuvo mejor efecto antiinflamatorio que la hidrocortisona (43). En una revisión de ocho ensayos clínicos, se evaluaron los efectos del consumo del $\mathrm{JN}$ sobre marcadores inflamatorios (NF-KB,CRP,LL-1,L-6,TLR) en individuos sin enfermedad cardiovascular o metabólica establecida, después de su consumo en el período posprandial o después de tomarlo durante al menos 7 días. El resultado fue una disminución de estos marcadores inflamatorios y de la expresión de genes proinflamatorios MCP-1, C-C Motif Chemokine Ligand 26 (CCL26) y C-X3-C Motif Chemokine Receptor 1 (CX3CR1) (44).

La evidencia sugiere que los compuestos activos actuarían de una forma sinérgica para cumplir sus propiedades antivirales, inmunomoduladoras y antiinflamatorias, aspecto importante en la búsqueda de un fármaco integral con dichas propiedades contra la COVID-19.

Curcuma longa L. Conocida como cúrcuma o "pali"lo", es una planta perenne herbácea perteneciente a la familia Zin- giberaceae. La parte de la planta que se utiliza es el rizoma (46) y sus principios activos más importantes son los curcuminoides (curcumina, demetoxicurcumina y bisdemetoxicurcumina) (47) y los aceites esenciales como la ar-turmerona, $\alpha$-turmerona y $\beta$-turmerona, entre otros (48). De los curcuminoides mencionados, la curcumina es el más estudiado y es el polifenol más abundante de la Curcuma longa.

La curcumina es una molécula pleiotrópica, cuya actividad inmunomoduladora fue comprobada en una investigación realizada en células caninas de riñón Madin-Darby (MDCK) con el virus de la influenza aviar (H5N1), en la que se observó la regulación de los niveles de IFN- $\beta$ y de TNF- $\alpha$, así como la expresión del RNAm $(49,50)$. 
También actúa regulando los niveles de citocinas inflamatorias como la MCP-1, la IL-6 y la TNF- $\alpha$, efecto observado en la infección con el virus de la influenza tipo $A$ en la línea celular de cáncer de pulmón humano A549 (51).

El efecto antiinflamatorio de la curcumina se evidenció en un estudio in vivo sobre lesiones de ratones. Esta actúa disminuyendo la TLR4 y $\mathrm{NF}-\kappa \mathrm{B}$, además evita una respuesta autoinmune en ratones infectados con la K. pneumoniae al reducir la infiltración leucocitaria a los pulmones y los niveles de NO y TNF- $\alpha$ (52). Otros componentes de la cúrcuma, como sus aceites esenciales ( $\alpha$-turmerona y ar-turmerona), han demostrado efecto antiinflamatorio utilizando macrófagos y ejerciendo actividades moduladoras sobre células mononucleares de sangre periférica (PBMC) de humanos (53). Estos hallazgos ponen en evidencia que diferentes compuestos de esta especie tienen efecto inmunomodulador, lo que implica la importancia de usar la cúrcuma como extracto total, en el que sus diferentes compuestos actuarían sinérgicamente.

Respecto a la actividad antiviral, la curcumina demostró efectividad al reducir la formación de partículas virales infecciosas del virus de la encefalitis japonesa en células de neuroblastoma infectadas a través de la desregulación del sistema ubiquitina-proteasoma; además posee una actividad antioxidante que ayuda a reducir los niveles de especies reactivas de oxígeno protegiendo a las células de apoptosis (54). También inhibe la replicación del virus de la hepatitis $C$ a través de la vía PI3K/Akt (55) y la infección del virus de la hepatitis $B$ al alterar la acetilación de las histonas ligadas a ADN circular cerrado covalentemente (ADNccc) (56). Así también, la curcumina reduce la replicación del virus de la influenza $A$ y evita la unión de las partículas virales con su receptor de ácido siálico en la superficie celular, este último mecanismo ha sido comprobado también en un subtipo del virus de la influenza H6N1(57).

En otras infecciones respiratorias causadas por virus como el MERS-CoV y el SARS-CoV, ha sido comprobada la efectividad del tratamiento con curcumina tanto sola como en combinación con la vitamina $\mathrm{C}$ y el ácido glicirricínico; su mecanismo de acción consiste en promover la proliferación de células Th1, así como anticuerpos específicos para estas infecciones $y$, al mismo tiempo, regula los subconjuntos Th1/ Th2 a fin de prevenir una respuesta autoinmune en etapas más avanzadas de la infección, por lo que es importante mencionar que este análisis biológico sistemático requiere de estudios in vivo e in vitro para validar estos resultados (58). En otro estudio, la curcumina y otros fitocompuestos demostraron niveles significativos de actividad anti-SARS-CoV con células Vero E6 (59).

Es importante señalar que esta planta también tiene una acción antitrombótica al inhibir el factor liberador de plaquetas y la agregación plaquetaria del ácido araquidónico, posiblemente al interferir con la síntesis del tromboxano A2 (60).

\section{Punica granatum L.}

Conocida comúnmente como granada, es un arbusto caducifolio que pertenece a la familia Lythraceae. Nativa de Irán y el Medio Oriente, actualmente es una especie cosmopolita (61). Los principales compuestos de esta especie son los polifenoles, en especial las AT y los taninos hidrolizables $(\mathrm{HT})$, estos últimos se agrupan en elagitaninos (ET) y galotaninos (GT). La cáscara de su fruto es rica en $\mathrm{HT}$, con predominio de ET, también contiene ácido elágico, punicalagina, entre otros; los flavonoides abundan en el arilo, el jugo y la cáscara (62). 
Con respecto al efecto inmunomodulador y su rol en la inflamación, se ha reportado in vitro una serie de mecanismos en el extracto y principios activos como el ácido elágico y taninos de la granada que son capaces de reducir distintos marcadores inflamatorios, disminuyendo así la respuesta innata por acción de los macrófagos $(63,64)$. Los estudios ponen en evidencia que el extracto de granada en macrófagos logra disminuir los niveles de expresión, activación, fosforilación y translocación nuclear de MAPK, ERK1/2, JNK, p38 y $\mathrm{NF}-\kappa \mathrm{B}$; por consiguiente, es capaz de atenuar los niveles de mediadores inflamatorios como IL-6, IL-17, IL-12, IL-8, IL-13, IL-5, IL-4, IL-18, PGE-2, NO, iNOS, COX-2, IL-2, e IL-1 $\beta$, entre otros (65).

Por otro lado, también se ha reportado un efecto inmunoestimulante. Los polisacáridos de la cáscara de granada indujeron la liberación de mediadores como NO, IL-1 $\beta$, TNF- $\alpha$, IL-6 e IL-10 en macrófagos in vitro (66), mientras que, en otro estudio, estos polisacáridos estimularon la proliferación y secreción de linfocitos espléni- cos y aumentaron notablemente la expresión de inmunoglobulinas (Ig-A, Ig-G e lg-M) y la libera- ción de citocinas (TNF- $\alpha$, IL-2 e INF- $\gamma$ ) en ratones inmunosuprimidos inducidos por ciclofosfamida (67). Adicional a esto, la granada ha sido analizada entre una serie de sustancias sintéticas y nutricionales, con el fin de encontrar un potencial abordaje inmunomodulador de la sobreproducción de citocinas para el tratamiento viral agresivo de la enfermedad pulmonar causada por COVID-19. Su mecanismo antiinflamatorio sería a través de la activación del receptor PPAR- $\gamma$ (68).

Con respecto a su efecto antiviral, hay una serie de estudios in vitro que demuestran que el extracto de cáscara de granada inhibe la replicación del virus de la influenza A (69). Se plantea que dicho mecanismo se asocia con la inhibición de la adsorción viral y la transcripción del ARN viral (70). En otros estudios, se ha evidenciado que el extracto estandarizado con $93 \%$ de polifenoles también tuvo una potente actividad antiviral contra cepas de la influenza A (X31, PR8, H1N1) y la cepa de coronavirus MHV A59 (71). Se ha probado que los polifenoles del extracto de granada (como la punicalagina) tendrían un papel clave al inhibir al virus de la influenza $A$, in vitro. Además, dicho extracto, al ser evaluado junto con el fármaco oseltamivir, logró potenciar el efecto de dicho fármaco (72). Por ello, los compuestos activos de esta fruta pueden ser una fuente prometedora para desarrollar nuevos medicamentos.

\section{Sambucus nigra L.}

Comúnmente conocida como sauco, pertenece a la familia Adoxaceae. La parte de la planta que se utiliza es el fruto y las bayas, en las que se encuentran componentes tales como ácidos orgánicos (ácido cítrico, málico, shikímico y fumárico), AT (principalmente cianidina 3-glucósido y cianidina 3-sambubiósido) y flavonoides (principalmente, quercetina 3-rutinósido y quer- cetina 3-glucósido) (73).

Respecto a la actividad inmunomoduladora, en modelos in vitro se ha reportado la disminución de la producción de mediadores inflamatorios TNF-ם, IL-6, PGE-2 y NO, por acción de extracto del fruto, como en el caso del extracto etanólico $(74,75)$. Por otra parte, el uso del jugo de saúco, mediante el compuesto cianidina 3-glucósido, incrementó significativamente la producción de IL-6, IL-8 y TNF (76). En estudios in vivo con especies murinas, el extracto de Sambucus nigra rico en polifenoles aumentó los valores de TNF- $\alpha$ y IFN- $\gamma(77)$.

Con respecto a la actividad antiviral del saúco, se ha observado un efecto contra el virus de la influenza aviar H9N2 probado en embriones de pollos tratados, previamente a la infección, con 
extracto de sauco (78). Otro estudio elucidó que los flavonoides son los principales contribuyentes a la actividad antiinfluenza del extracto de saúco: estos incapacitan a los virus H1N1 para ingresar a las células huésped, previniendo efectivamente la infección (79). El extracto etanólico mostró su potencial efecto inhibidor de coronavirus IBV, al inactivarlo y comprometer la integridad de su membrana y otras estructuras del virión en células Vero (80). El extracto etanólico de una de las variedades del sauco, el Sambucus formosana Nakai, también presentó actividad contra la replicación de un coronavirus, el HCoVNL63 (81).

El extracto etanólico de Sambucus nigra demostró un efecto inmunomodulador y presentó actividad contra el virus de la influenza y el subtipo H1N1. Además, un miembro del género Sambucus tiene potencial actividad contra un tipo de coronavirus humano, el HCoVNL63.

\section{Vitis vinifera $\mathrm{L}$.}

Es un fruto cosmopolita comúnmente conocido como uva, que pertenece a la familia Vitaceae. Es consumido en distintas presentaciones: fruto, jugo, vino y orujo de uva (82). Dentro de sus principales compuestos están los fenoles, los cuales incluyen a los estilbenoides, siendo el más estudiado de este grupo el resveratrol (83). Este compuesto es una fitoalexina que actúa como un antimicrobiano producido por las plantas en respuesta a infecciones fúngicas o estrés fisiológico. Las semillas de la uva contienen proantocianidinas (84).

El resveratrol modula la respuesta inflamatoria de forma pleiotrópica, tiene efecto antioxidante y se está estudiando su importancia en el tratamiento de infecciones virales, in vitro e in vivo (85). Se tiene evidencia de que el resveratrol disminuye los niveles del virus de la pseudorrabia en lechones infectados (86); este compuesto también demos- tró su capacidad para inhibir la replicación del coronavirus del MERS-CoV in vitro, a través de la inhibición de la producción de ARN viral intracelular, entre otros mecanismos (87).

El extracto de semilla de uva, rico en flavonoides y fenoles, puede inhibir la expresión de citocinas derivadas de la respuesta Th2, como la IL-6, e inducir selectivamente la producción de citocinas derivadas de Th1 por PBMC, en quienes muestra efectos variables en la producción de IFN- $\gamma$ (88). El principal oligómero de este extracto es la procianidina $B 1$, que tiene efectos antihepatitis $C$ mediante la supresión de la expresión celular de COX-2 a través de la inactivación de las vías de señalización NF-KB y ERK / JNK MAPK (89).

Las proantocianidinas, un tipo de flavonoides presentes en la semilla de uva, pueden tener efectos estimuladores sobre la inmunidad celular, promover la proliferación de linfocitos, mejorar la fagocitosis de macrófagos peritoneales y aumentar la liberación de moléculas efectoras producidas por macrófagos (90). En un estudio clínico, el extracto de proantocianidina de semilla de uva (EPSU) se utilizó como pretratamiento para regular la respuesta inmune, suprimiendo la expresión de IL-1 $\beta$, IL-6 e IL-8 inducida por el virus sincitial respiratorio (VSR). Esto sugirió que el EPSU es un agente preventivo en enfermedades respiratorias inducidas por el VSR (84).

Esta fruta contiene tres compuestos activos (resveratrol, proantocianidinas y fenoles) con potencial efecto contra la replicación viral de tres tipos de coronavirus, entre ellos el SARS-CoV-2. Asimismo, su evidente efecto regulador en la respuesta celular es un factor importante en la defensa contra infecciones virales. 


\section{Zingiber officinale Rosc}

Conocida comúnmente como kion o jengibre, es una planta que pertenece a la familia Zingiberaceae y es nativa de la India o el Sudeste Asiático. Se cultiva en todas las zonas tropicales del planeta y se aprovechan sus rizomas medicinales y alimenticios. En los rizomas frescos, los gingeroles son los principales compuestos activos, siendo el más destacado el 6-gingerol. Los gingeroles, al ser deshidratados, se convierten en shogaoles, por lo que, en sus rizomas secos, el shogaol es el compuesto predominante $(91,92)$. Los principales compuestos fenólicos y flavonoides hallados son el ácido clorogénico y la hesperidina, mientras que los principales aceites esenciales son el curcumeno y el linalol (93).

Su acción inmunomoduladora se evidencia en su efecto antiinflamatorio a través de la inhibición de linfocitos Th1 y Th2, supresión de genes que expresan IFN- $\gamma$ e IL-4, así como la disminución del factor de transcripción Activator-protein 1 (AP1) y de la vía NF-кB por acción del 6-gingerol (94). También se han reportado dichos efectos en el extracto acuoso de kion (rico en gingeroles, shogaol y paradol), en roedores con edema plantar inducido por carragenina. El resultado de la dosis dependiente de la inhibición del edema fue equiparable al efecto de la indometacina; el mecanismo involucrado fue la inhibición de la activación de macrófagos y neutrófilos, y de la migración de monocitos y leucocitos. A nivel molecular, se observó la disminución de citoquinas proinflamatorias (TNF $\alpha$, IL-6, IL-1 $\beta$, MCP-1) y quimiocinas, así como la restauración de la capacidad antioxidante (91).

El efecto antiviral de esta especie se evidencia en estudios contra el VSR, VIH-1 pseudovirus y en coronavirus $(95,96)$. Un estudio in silico con- tra SARS-CoV-2 muestra que el 6-gingerol posee potencial afinidad a residuos activos 31 Lys y 353 Lys del receptor de la ACE2, lo cual dificultaría el ingreso del virus (97).

En un ensayo clínico aleatorizado, realizado en 120 adultos mayores de entre 50 a 70 años con diagnóstico de osteoartritis, se administró una cápsula de $500 \mathrm{mg}$ de jengibre en polvo dos veces al día durante tres meses. Se evidenció que las concentraciones séricas de TNF- $\alpha$ e IL- $1 \beta$ eran menores en el grupo experimental. También se observó la inhibición de PGE-2 y la supresión de la enzima COX-2 (98). En otro ensayo clínico, con 32 pacientes diagnosticados con síndrome de dificultad respiratoria aguda, se evaluó el efecto de una dieta enteral enriquecida con extracto de kion; el resultado fue una disminución en los niveles séricos de IL-1, IL-6, TNF- $\alpha$ y leucotrieno B4 en el décimo día de estudio. No se observó diferencia en cuanto a la mortalidad de los grupos de estudio (99). Lo anterior sugiere que el Zingiber officinale posee efectos inmunomoduladores, antivirales y antiinflamatorios prometedores para futuras investigaciones.

En conclusión, la evidencia sugiere la potencialidad de estos compuestos presentes en los alimentos, muchos consumidos en una dieta cotidiana, como principios activos farmacológicos con propiedades inmunomoduladoras, inmunoestimulantes 0 antivirales. En esta revisión, se lograron identificar nueve alimentos con dichas propiedades contra el coronavirus, de los cuales cuatro alimentos reportaron efectos en SARS-Cov-2. Cabe resaltar que la mayoría de estas investigaciones son estudios de acoplamiento molecular y experimentales, por lo que aún faltan investigaciones preclínicas y clínicas para verificar su acción potencial contra el nuevo coronavirus. Además, es importante que los nuevos estudios evalúen también la efectividad que estos alimentos tienen desde un enfoque preventivo mediante su consumo. 
Alimentos con potencial efecto inmunomodulador y antiviral

\section{AGRADECIMIENTOS}

A los revisores que aportaron con sus sugerencias y optimización de la información en la investigación.

\section{FINANCIACIÓN}

La presente revisión narrativa fue autofinanciada.

\section{CONFLICTO DE INTERESES}

Los autores declaran que no hay conflicto de intereses.

\section{- -Referencias}

1. World Health Organization Press Conference The World Health Organization (WHO) Has Officially Named the Disease Caused by the Novel Coronavirus as COVID-19. [Citado agosto de 2021]. Disponible en: https://www.who.int/emergencies/diseases/novel-coronavirus-2019/technical-guidance/naming-the-coronavirus-disease-(covid-2019)-and-the-virus-that-causes-it

2. The World Health Organization (WHO). [Citado agosto de 2021). Disponible en: https://covid19.who.int/

3. Lu G, Wang Q, Gao GF. Bat-to-human: Spike features determining 'host jump' of coronaviruses SARS-CoV, MERS-CoV, and beyond. Trends Microbiol. 2015;23(8):468-78. https://doi.org/10.1016/j.tim.2015.06.003

4. Yang Y, Peng F, Wang R, Guan K, Jiang T, Xu G, et al.. The deadly coronaviruses: The 2003 SARS pandemic and the 2020 novel coronavirus epidemic in China. J Autoimmun. 2020;109:102434. https://doi.org/10.1016/j.jaut.2020.102434

5. Wu C, Liu Y, Yang Y, Zhang P, Zhong W, Wang Y, et al. Analysis of therapeutic targets for SARS-CoV-2 and discovery of potential drugs by computational methods. Acta Pharm Sin B. 2020;10:766-88. https://doi.org/10.1016/j.apsb.2020.02.008

6. Jin Y, Yang H, Ji W, Wu W, Chen S, Zhang W, et al. Virology, epidemiology, pathogenesis, and control of COVID-19. Viruses. 2020;12(4):372. https://doi.org/10.3390/v12040372

7. Elfiky AA. Natural products may interfere with SARS-CoV-2 attachment to the host cell. J Biomol Struct Dyn. 2021;39(9):3194-203. https://doi.org/10.1080/07391102.2020.176188

8. Sohrabi C, Alsafi Z, O'Neill N, Khan M, Kerwan A, Al-Jabir A, et al. World Health Organization declares global emergency: A review of the 2019 novel coronavirus (COVID-19). Int J Surg. 2020;76:71-6. https://doi.org/10.1016/j.jisu.2020.02.034

9. Santos-Buelga C, González-Paramás AM, Oludemi T, Ayuda-Durán B, González-Manzano S. Plant phenolics as functional food ingredients. Adv Food Nutr Res. 2019;90:183-257. https://doi.org/10.1016/bs.afnr.2019.02.012

10. Candeias NR, Assoah B, Simeonov SP. Production and synthetic modifications of shikimic acid. Chem Rev. 2018;118(20):10458-550. https://doi.org/10.1021/acs.chemrev.8b00350

11. Batiha GE, Beshbishy AM, Wasef LG. Chemical constituents and pharmacological activities of garlic (Allium sativum L.): A review. Nutrients. 2020;12(3):1-21. https://doi.org/10.3390/nu12030872 
12. Bae CH, Kwak DS, Ye SB, Song SY, Kim YD. Diallyl disulfide induces MUC5B expression via ERK2 in human airway epithelial cells. Phytother Res. 2012;26(2):197-203. https://doi.org/10.1002/ptr.3531

13. Sharma N. Efficacy of garlic and onion against virus. Int J Res Phamaceutical Sci. 2019;10(4):3578-86. https://doi.org/10.26452/ijps.v10i4.1738

14. Dwivedi VP, Bhattacharya D, Singh M, Bhaskar A, Kumar S, Sobia $P$, et al. Allicin enhances antimicrobial ac- tivity of macrophages during Mycobacterium tuberculosis infection. J Ethnopharmacol. 2018;243:1116-34. https://doi.org/10.1016/j.jep.2018.12.008

15. Chandrashekara PM, Venkatesh YP. Immunostimulatory properties of fructans derived from raw garlic (Allium sativum L.). Bioact Carbohydrates Diet Fibre 2016;8(2):65-70. https://doi.org/10.1016/j.bcdf.2016.11.003

16. Clement $\mathrm{F}$, Pramod SN, Venkatesh YP. Identity of the immunomodulatory proteins from garlic (Allium sativum) with the major garlic lectins or agglutinins. Int Immunopharmacol. 2010;10(3):316-24. https://doi.org/10.1016/j.intimp.2009.12.002

17. Guillamón E. Effect of phytochemical compounds of the genus Allium on the immune system and the inflammatory response. Ars Pharm. 2018;59(3):185-196. https://doi.org/10.30827/ars.v59i3.7479

18. Weber ND, Andersen D, North JA, Murray BK, Lawson LI, Hughes BG. In vitro virucidal effects of Allium sativum (Garlic) extract and compounds. Planta Med. 1991;58(5):417-23. https://doi.org/10.1055/s-2006-961504

19. Chavan RD, Shinde P, Girkar K, Madage R, Chowdhary A. Assessment of anti-influenza activity and hema- gglutination inhibition of plumbago indica and Allium sativum Extracts. Pharmacognosy Res. 2016;8(2):105-11. https://doi.org/10.4103/0974-8490.172562

20. Shojai TM, Ghalyanchi A, Karimi V, Barin A, Sadri N. The effect of Allium sativum (Garlic) extract on infectious bronchitis virus in specific pathogen free embryonic egg. Avicenna J Phytomed. 2016;6(4):458-67. Disponible en: https://www.ncbi.nlm.nih.gov/pmc/articles/PMC4967842/pdf/AJP-6-458.pdf

21. Thuy BTP, My TTA, Hai NTT, Hieu LT, Hoa TT, Phuong TH, et al. Investigation into SARS-CoV-2 resistance of compounds in garlic essential oil. ACS omega. 2020; 5(14):8312-20. https://doi.org/10.1021/acsomega.0c00772

22. López MT. El ajo propiedades farmacológicas e indicaciones terapéuticas. Offarm. 2007;26(1):79-81. Disponible en: https://www.elsevier.es/es-revista-offarm-4-pdf-13097334

23. Fredotović Ž, Šprung M, Soldo B, Ljubenkov I, Budić-Leto I, Bilušić T, et al. Chemical composition and biological activity of Allium cepa L. and Allium $\times$ cornutum (Clementi ex Visiani 1842) methanolic extracts. Molecules. 2017;22(3):448. https://doi.org/10.3390/molecules22030448

24. Hanieh $\mathrm{H}$, Narabara K, Piao M, Gerile C, Abe A, Kondo Y. Modulatory effects of two levels of dietary Alliums on immune response and certain immunological variables, following immunization, in White Leghorn chickens. Anim Sci J. 2010;81(6): 673-80. https://doi.org/10.1111/j.1740-0929.2010.00798.x

25. Elberry AA, Mufti S, Al-Maghrabi J, Abdel Sattar E, Ghareib SA, Mosli HA, et al. Immunomodulatory effect of red onion (Allium cepa Linn) scale extract on experimentally induced atypical prostatic hyperplasia in Wistar rats. Mediators Inflamm. 2014; 2014:640746. https://doi.org/10.1155/2014/640746

26. Oliveira TT, Campos KM, Cerqueira-Lima AT, et al. Potential therapeutic effect of Allium cepa L. and quercetin in a murine model of Blomia tropicalis induced asthma. Daru. 2015;23(1):18. https://doi.org/10.1186/s40199-015-0098-5

27. Kuttan G. Immunomodulatory effect of some naturally occuring sulphur-containing compounds. J Ethnopharmacol. 2000; 72(1-2),93-9. https://doi.org/10.1016/S0378-8741(00)00211-7 


\section{Alimentos con potencial efecto inmunomodulador y antiviral}

28. Kumar VP, Prashanth KVH, Venkatesh YP. Structural analyses and immunomodulatory properties of fructo-oligosaccharides from onion (Allium cepa). Carbohydr Polym. 2015;117:115-22. https://doi.org/10.1016/j.carbpol.2014.09.039

29. Kumar VP, Venkatesh YP. Alleviation of cyclophosphamide-induced immunosuppression in Wistar rats by onion lectin (Allium cepa agg/utinin). J. Ethnopharmacol. 2016;186:280-8. https://doi.org/10.1016/j.jep.2016.04.006

30. Prasanna VK, Venkatesh YP. Characterization of onion lectin (Allium cepa agglutinin) as an immunomodulatory protein inducing Th1-type immune response in vitro. Int Immunopharmacol. 2015;26(2):1-10. https://doi.org/10.1016/j.intimp.2015.04.009

31. Batiha G, Beshbishy A, Mulla Z, Ikram M, El-Hack, M, Taha AE. The pharmacological activity, biochemical properties, and pharmacokinetics of the major natural polyphenolic flavonoid: Quercetin. foods. 2020;9(3):374. https://doi.org/10.3390/foods9030374

32. Yi L, Li Z, Yuan K, Qu X, Chen J, Wang G, et al. Small molecules blocking the entry of severe acute respiratory syndrome coronavirus into host cells. J Virol. 2004;78(20):11334-9. https://doi.org/10.1128/JVI.78.20.11334-11339.2004

33. Nguyen TTH, Woo H-J, Kang H-K, Nguyen VD, Kim Y-M, Kim D-W, et al. Flavonoid-mediated inhibition of SARS coronavirus 3C-like protease expressed in Pichia pastoris. Biotechnol Lett. 2012;34(5):831-8. https://doi.org/10.1007/s10529-011-0845-8

34. Kumar S, Kumari R, Mishra S. Pharmacological properties and their medicinal uses of Cinnamomum: a review. J Pharm Pharmacol. 2019;71(12):1735-61. https://doi.org/10.1111/jphp.13173

35. Cao H, Urban J, Anderson R. Cinnamon polyphenol extract affects immune responses by regulating anti- and proinflammatory and glucose transporter gene expression in mouse macrophages. J Nutr. 2008;138(5):833-40. https://doi.org/10.1093/jn/138.5.833

36. Hagenlocher $Y$, Hösel A, Bischoff S, Lorentz A. Cinnamon extract reduces symptoms, inflammatory mediators and mast cell markers in murine IL-10(-/-) colitis. J Nutr Biochem. 2016;30:85-92. https://doi.org/10.1016/j.jnutbio.2015.11.015

37. Beom-Joon L, Youn-Jung K, Dong-Hyung C, Nak-Won S, Hee K. Immunomodulatory effect of water extract of cinnamon on anti-CD3-induced cytokine responses and p38, JNK, ERK1/2, and STAT4 activation. Immunopharmacol Immunotoxicol. 2011;33(4):714-22. https://doi.org/10.3109/08923973.2011.564185

38. Orihara Y, Hamamoto H, Kasuga H, Shimada T, Kawaguchi Y, Sekimizu K. A silkworm-baculovirus model for assessing the therapeutic effects of antiviral compounds: Characterization and application to the isolation of antivirals from traditional medicines. J Gen Virol. 2008;89(1):188-94. https://doi.org/10.1099/vir.0.83208-0

39. Liu L, Wei F, Qu Z, Wang S, Chen G, Gao H, et al. The antiadenovirus activities of Cinnamaldehyde in vitro. Science. 2009;40(11):669-74. https://doi.org/10.1309/LMF0U47XNDKBZTRQ

40. Connell BJ, Chang S-Y, Prakash E, Yousfi R, Mohan V, Posch W, et al. A cinnamon-derived procyanidin compound displays anti-HIV-1 activity by blocking heparan sulfate- and co-receptor- binding sites on gp120 and reverses t cell exhaustion via impeding Tim-3 and PD-1 upregulation. PLoS One. 2016;11(10):e0165386. https://doi.org/10.1371/journal.pone.0165386

41. Ademosun AO, Oboh $\mathrm{G}$. Anticholinesterase and antioxidative properties of water-extractable phytochemicals from some citrus peels. J Basic Clin Physiol Pharmacol. 2014;25(2):199-204. https://doi.org/10.1515/jbcpp-2013-0027

42. Cheng L, Zheng W, Li M, Huang J, Bao S, Xu Q , et al. Citrus fruits are rich in flavonoids for immunoregulation and potential targeting ACE2. Preprints. 2020. https://www.preprints.org/manuscript/202002.0313/v1

43. Cardile V, Frasca G, Rizza L, Rapisarda P, Bonina F. Antiinflammatory effects of a red orange extract in human keratinocytes treated with interferon-gamma and histamine. Phytother Res. 2010;24(3):414-8. https://doi.org/10.1002/ptr.2973

44. Coelho RC, Hermsdorff HH, Bressan J. Anti-inflammatory properties of orange juice: Possible favorable molecular and metabolic effects. Plant Foods Hum Nutr. 2013;68(1):1-10. https://doi.org/10.1007/s11130-013-0343-3 
45. Ulasli M, Gurses SA, Bayraktar R, Yumrutas O, Oztuzco S, Igci M, et al. The effects of Nigella sativa (Ns), Anthemis hyalina (Ah) and Citrus sinensis (Cs) extracts on the replication of coronavirus and the expression of TRP genes family. Mol Biol Rep. 2014;41(3):1703-11. https://doi.org/10.1007/s11033-014-3019-7

46. Clapé $\mathrm{O}$, Alfonso A. Avances en la caracterización farmacotoxicológica de la planta medicinal Curcuma longa Linn. Medisan. 2012;16(1):97-114. Disponible en: http://scielo.sld.cu/pdf/san/v16n1/san13112.pdf

47. García LL, Olaya JH, Sierra JI, Padilla L. Actividad biológica de tres Curcuminoides de Curcuma longa L. (Cúrcuma) cultivada en el Quindío-Colombia. Rev Cubana Plant Med. 2017;22(1). Disponible en: http://scielo.sld.cu/pdt/pla/v22n1/pla07117.pdf

48. Dosoky NS, Setzer WN. Chemical composition and biological activities of essential oils of curcuma species. Nutrients. 2018;10(9):1196. https://doi.org/10.3390/nu10091196

49. Gupta SC, Patchva S, Aggarwal BB. Therapeutic roles of curcumin: Lessons learned from clinical trials. AAPS J. 2013;15(1):195-218. https://doi.org/10.1208/s12248-012-9432-8

50. Sornpet B, Potha T, Tragoolpua Y, Pringproa K. Antiviral activity of five Asian medicinal pant crude extracts against highly pathogenic H5N1 avian influenza virus. Asian Pac J Trop Med. 2017;10(9):871-6. https://doi.org/10.1016/..apjtm.2017.08.010

51. Han $\mathrm{S}, \mathrm{Xu}$ J, Guo X, Huang M. Curcumin ameliorates severe influenza pneumonia via attenuating lung injury and regulating macrophage cytokines production. Clin Exp Pharmacol Physiol. 2018;45(1):84-93. https://doi.org/10.1111/1440-1681.12848

52. Catanzaro M, Corsini E, Rosini M, Racchi M, Lanni C. Immunomodulators inspired by nature: A review on curcumin and echinacea. molecules. 2018;23(11):2778. https://doi.org/10.3390/molecules23112778

53. Yue GG, Chan BC, Hon PM, et al. Evaluation of in vitro anti-proliferative and immunomodulatory activities of compounds isolated from Curcuma longa. Food Chem Toxicol. 2010;48(8-9):2011-20. https://doi.org/10.1016/.fft.2010.04.039

54. Dutta K, Ghosh D, Basu A. Curcumin protects neuronal cells from Japanese encephalitis virus-mediated cell death and also inhibits infective viral particle formation by dysregulation of ubiquitin-proteasome system. J Neuroimmune Pharmacol. 2009;4(3):328-37. https://doi.org/10.1007/s11481-009-9158-2

55. Kim K, Kim KH, Kim HY, Cho HK, Sakamoto N, Cheong J. Curcumin inhibits hepatitis $\mathrm{C}$ virus replication via suppressing the Akt-SREBP-1 pathway. FEBS Lett. 2010;584(4):707-12. https://doi.org/10.1016/j.febslet.2009.12.019

56. Wei ZQ, Zhang $\mathrm{YH}, \mathrm{Ke} \mathrm{CZ}$, et al. Curcumin inhibits hepatitis $\mathrm{B}$ virus infection by down-regulating $\operatorname{cccDNA}$-bound histone acetylation. World Journal of Gastroenterology. 2017;23(34):6252. https://doi.org/10.3748/wjg.v23.i34.6252

57. Chen DY, Shien JH, Tiley L, Chiou SS, Wang SY, Chang TJ, et al. Curcumin inhibits influenza virus infection and haemagglutination activity. Food Chemistry. 2010;119(4):1346-51. https://doi.org/10.1016/j.foodchem.2009.09.011

58. Chen L, Hu C, Hood M, Zhang X, Zhang L, Kan J, et al. A novel combination of vitamin C, curcumin and glycyrrhizic acid potentially regulates immune and inflammatory response associated with coronavirus infections: A perspective from system biology analysis. nutrients. 2020;12(4):1193. https://doi.org/10.3390/nu12041193

59. Wen CC, Kuo YH, Jan JT, Liang PH, Wang SY, Liu HG, et al. Specific plant terpenoids and lignoids possess po- tent antiviral activities against severe acute respiratory syndrome coronavirus. J Med Chem. 2007;50(17):4087-95. https://doi.org/10.1021/jm070295s

60. Shah BH, Nawaz Z, Pertani SA. Efecto inhibidor de la curcumina, una especia alimenticia de la cúrcuma, sobre la agregación plaquetaria mediada por el factor activador de plaquetas y el ácido araquidónico a través de la inhibición de la formación de tromboxano y la señalización de Ca2 +. Biochem Pharmacol. 1999;58:1167-72. https://doi.org/10.1016/S0006-2952(99)00206-3 


\section{Alimentos con potencial efecto inmunomodulador y antiviral}

61. Shaygannia E, Bahmani M, Zamanzad B, Rafieian-Kopaei M. A review study on Punica granatum L. J Evid Based Complementary Altern Med. 2016;21(3):221-7. https://doi.org/10.1177/2156587215598039

62. Wu S, Tian L. Diverse phytochemicals and bioactivities in the ancient fruit and modern functional food pomegranate (Punica granatum). Molecules. 2017;22(10):1606. https://doi.org/10.3390/molecules22101606

63. Shukla M, Gupta K, Rasheed Z, Khan KA, Haqqi TM. Consumption of hydrolyzable tannins-rich pomegrana- te extract suppresses inflammation and joint damage in rheumatoid arthritis. Nutrition. 2008;24(7-8):733-43. https://doi.org/10.1016/j.nut.2008.03.013

64. Shuang G, Yiying Z, Xin Y, Wanlu L, Bing H, Jing L. Ellagic acid protects against LPS-induced acute lung injury through inhibition of nuclear factor kappa B, proinflammatory cytokines and enhancement of interleukin-10. Food Agric Immunol. 2017;28(6):1347-61. https://doi.org/10.1080/09540105.2017.1339670

65. Rahimi VB, Ghadiri M, Ramezani M, Askari VR. Antiinflammatory and anti-cancer activities of pomegranate and its constituent, ellagic acid: Evidence from cellular, animal, and clinical studies. Phytother Res. 2020;34(4):685-720. https://doi.org/10.1002/ptr.6565

66. Gavlighi HA, Tabarsa M, You S, Surayot U, Ghaderi-Ghahfarokhi M. Extraction, characterization and immunomodulatory property of pectic polysaccharide from pomegranate peels: Enzymatic vs conventional approach. Int J Biol Macromol. 2018;116:698-706. https://doi.org/10.1016/j.ijbiomac.2018.05.083

67. Wu Y, Zhu CP, Zhang Y, Li Y, Sun JR. Immunomodulatory and antioxidant effects of pomegranate peel polysaccharides on immunosuppressed mice. Int J Biol Macromol. 2019;137:504-11. https://doi.org/10.1016/j.ijbiomac.2019.06.139

68. Ciavarella C, Motta I, Valente S, Pasquinelli G. Pharmacological (or synthetic) and nutritional agonists of PPAR- $\square$ as can- didates for cytokine storm modulation in COVID-19 disease. Molecules. 2020;25(9):E2076. https://doi.org/10.3390/molecu- les25092076

69. Moraldi MT, Karimi A, Shahrani M, Hashemi L, Ghaffari-Goosheh MS. Anti-influenza virus activity and phenolic content of pomegranate (Punica granatum L.) peel extract and fractions. Avivenna J Med. Biotechnol. 2019;11(4):285-91. Disponible en: https://www.ncbi.nlm.nih.gov/pmc/articles/PMC6925405

70. Moradi MT, Karimi A, Rafieian-Kopaei M, Rabiei-Faradonbeh M, Momtaz H. Pomegranate peel extract inhibits internalization and replication of the influenza virus: An in vitro study. Avicenna J Phytomed. 2020;10(2):143-51. Disponible en: https://www.ncbi.nlm.nih.gov/pmc/articles/PMC7103433/

71. Sundararajan A, Ganapathy R, Huan L, Dunlap JR, Webby RJ. Kotwa GJ, et al. Influenza virus variation in susceptibility to inactivation by pomegranate polyphenols is determined by envelope glycoproteins. Antiviral Res. 2010;88(1):1-9. https://doi.org/10.1016/j.antiviral.2010.06.014

72. Haidari M, Ali M, Ward Casscells S 3rd, Madjid M. Pomegranate (Punica granatum) purified polyphenol extract inhibits influenza virus and has a synergistic effect with oseltamivir. Phytomedicine. 2009;16(12):1127-36. https://doi.org/10.1016/j. phymed.2009.06.002

73. Veberic R, Jakopic J, Stampar F, Schmitzer V. European elderberry (Sambucus nigra L.) rich in sugars, organic acids, anthocyanins and selected polyphenols. Food Chemistry. 2009;114(2):511-5. https://doi.org/10.1016/j.foodchem.2008.09.080

74. Zielińska-Wasielica J , Olejnik A, Kowalska K, Olkowicz M, Dembczyński R. Elderberry (Sambucus nigra L.) Fruit extract alleviates oxidative stress, insulin resistance, and inflammation in hypertrophied 3T3-L1 adipocytes and activated RAW 264.7 Macrophages. Foods. 2019;8(8):326. https://doi.org/10.3390/foods8080326 
75. Thanh G, Wangensteen H, Barsett $H$. Elderberry and elderflower extracts, phenolic compounds, and metabolites and their effect on complement, RAW 264.7 macrophages and dendritic cells. Int. J. Mol. Sci. 2017;18(3):584. https://doi.org/10.3390/ ijms18030584

76. Torabian G, Valtchev P, Adil Q, Dehghan F. Anti-influenza activity of elderberry (Sambucus nigra). J Funct Foods. 2019;54(1):353-60. https://doi.org/10.1016/j.jff.2019.01.031

77. Badescu M, Badulescu O, Badescu L, Ciocoiu M. Effects of Sambucus nigra and Aronia melanocarpa extracts on immune system disorders within diabetes mellitus. Pharm Biol. 2015;53(4):533-9. https://doi.org/10.3109/13880209.2014.931441

78. Karimi S, Mohammadi A, Dadras H. The effect of Echinacea purpurea and Sambucus nigra L. on H9N2 avian influenza virus in infected chicken embryo. Veterinarski Arhiv. 2014;84(2):153-65. Disponible en: http://intranet.vef.hr/vetarhiv/pa- pers/2014-84-2-5.pdf

79. Roschek B, Fink R, McMichael M, Li D, Alberte R. Elderberry flavonoids bind to and prevent H1N1 infection in vitro. Phytochemistry. 2009;70(10):1255-61. https://doi.org/10.1016/j.phytochem.2009.06.003

80. Chen C, Zuckerman DM, Brantley S, Sharpe S, Childress K, Hoiczyk E, et al. Sambucus nigra extracts inhibit infectious bronchitis virus at an early point during replication. BMC Vet Res. 2014;10(24). https://doi.org/10.1186/1746-6148-10-24

81. Weng JR, Lin CS, Lai HC, Lin YP, Wang CY, Tsai YC, et al. Antiviral activity of Sambucus Formosana Nakai ethanol extract and related phenolic acid constituents against human coronavirus NL63. Virus Res. 2019;273:197767. https://doi.org/10.1016/j.virusres.2019.197767

82. Ali K, Maltés F, Choi Y, Verpoorte R. Metabolic constituents of grapevine metabólicos de la vid y productos derivados de la uva. Fhytochem Rev. 2010;9(3):357-8. https://doi.org/10.1007/s11101-009-9158-0

83. Riviere C, Pawlus AD, Merillon JM. Natural stilbenoids: distribution in the plant kingdom and chemotaxonomic interest in Vitaceae. Nat Prod Rep. 2012;29(11):1317-33. https://doi.org/10.1039/c2np20049j

84. Kim SJ, Lee JW, Eun YG, Lee KH, Yeo SG, Kim SW. Pretreatment with a grape seed proanthocyanidin extract downregulates proinflammatory cytokine expression in airway epithelial cells infected with respiratory syncytial virus. Mol Med Rep. 2019;19(4):3330-6. https://doi.org/10.3892/mmr.2019.9967

85. Campagna M, Rivas C. Antiviral activity of resveratrol. Biochem Soc Trans. 2010;38:50-3. https://doi.org/10.1042/BST0380050

86. Zhao $X$, Tong $W$, Song $X$, et al. Antiviral effect of resveratrol in piglets infected with virulent pseudorabies virus. Viruses. 2018;10(9):457-67. https://doi.org/10.3390/v10090457

87. Lin S-C, Ho C-T, Chuo W-H, Li S, Wang TT, Lin C-C. Effective inhibition of MERS-CoV infection by resveratrol. BMC Infect Dis. 2017;17(1):144. https://doi.org/10.1186/s12879-017-2253-8

88. Nair N, Mahajan S, Chawda R, Kandaswami C, Shanahan T, Schwartz S, et al. Grape seed extract activates Th1cells in vitro Clin Diagn Lab Immunol. 2002;9(2):470-6. https://doi.org/10.1128/CDLI.9.2.470-476.2002

89. Chen WC, Tseng CK, Chen BH, Lin CK, Lee JC. Grape Seed extract attenuates hepatitis C virus replication and virus-induced inflammation. Front Pharmacol. 2016;7:490. https://doi.org/10.3389/fphar.2016.00490

90. Tong H, Song X, Sun X, Sun G, Du F. Immunomodulatory and antitumor activities of grape seed proanthocyanidins . J Agric Food Chem. 2011;59(21):11543-7. https://doi.org/10.1021/jf203170k

91. Ezzat SM, Ezzat MI, Okba MM, Menze ET, Abdel-Naim AB. The hidden mechanism beyond ginger (Zingiber officinale Rosc.) potent in vivo and in vitro anti-inflammatory activity. J Ethnopharmacol. 2018;214:113-23. https://doi.org/10.1016/j. jep.2017.12.019 


\section{Alimentos con potencial efecto inmunomodulador y antiviral}

92. Feng T, Su J, Ding ZH, et al. Chemical constituents and their bioactivities of "Tongling White Ginger" (Zingiber officinale). J Agric Food Chem. 2011;59(21):11690-5. https://doi.org/10.1021/jf202544w

93. Fahmi A, Hassanen N, Abdur-Rahman M, Shams-Eldin E. Phytochemicals, antioxidant activity and hepatoprotective effect of ginger (Zingiber officinale) on diethylnitrosamine toxicity in rats. Biomarkers. 2019;24(5):436-47. https://doi.org/10.1080/1 354750X.2019.1606280

94. Kawamoto $Y$, Ueno $Y$, Nakahashi E, et al. Prevention of allergic rhinitis by ginger and the molecular basis of immunosuppression by 6-gingerol through T cell inactivation. J Nutr Biochem. 2016;27:112-22. https://doi.org/10.1016/j.jnutbio.2015.08.025

95. Chang JS, Wang KC, Yeh CF, Shieh DE, Chiang LC. Fresh ginger (Zingiber officinale) has anti-viral activity against human respiratory syncytial virus in human respiratory tract cell lines. J Ethnopharmacol. 2013;145(1):146-51. https://doi.org/10.1016/j.jep.2012.10.043

96. Jayasundar R, Ghatak S, Makhdoomi MA, Luthra K, Singh A, Velpandian T. Challenges in integrating component level technology and system level information from Ayurveda: Insights from NMR phytometabolomics and anti-HIV potential of select Ayurvedic medicinal plants. J Ayurveda Integr Med. 2019;10(2):94-101. https://doi.org/10.1016/j.jaim.2017.06.002

97. Sivaraman D, Pradeep PS. Scope of phytotherapeutics in targeting ACE2 mediated Host-Viral Interface of SARS-CoV2 that causes COVID-19. Chem Rxiv. 2020. https://doi.org/10.26434/chemrxiv.12089730

98. Mozaffari-Khosravi H, Naderi Z, Dehghan A, Nadjarzadeh A, Fallah Huseini H. Effect of ginger supplementation on proinflammatory cytokines in older patients with osteoarthritis: Outcomes of a randomized controlled clinical trial. J Nutr Gerontol Geriatr. 2016;35(3):209-18. https://doi.org/10.1080/21551197.2016.1206762

99. Vahdat-Shariatpanahi Z, Mokhtari M, Taleban FA, Alavi F, Surmaghi M, Mehrabi Y, et al. Effect of enteral feeding with ginger extract in acute respiratory distress syndrome. J Crit Care. 2013;28(2):217. https://doi.org/10.1016/j.jcrc.2012.04.017 